\title{
Associations Between the 20II Great East Japan Earthquake and Tsunami and the Sleep and Mental Health of Japanese People: A 3-Wave Repeated
} Survey

Yu Itoh, (D) ' Masahiro Takeshima, (D) Yoshitaka Kaneita, ${ }^{2}$

Naohisa Uchimura, ${ }^{3}$ Yuichi Inoue, ${ }^{4}$

Makoto Honda, ${ }^{5}$ Wataru Yamadera, ${ }^{6}$

Norio Watanabe, ${ }^{7}$

Shingo Kitamura, iD ${ }^{8}$ Isa Okajima,

Naoko Ayabe, ${ }^{10}$

Kyoko Nomura, (iD) ${ }^{\prime \prime}$

Kazuo Mishima (iD)

'Department of Neuropsychiatry, Akita University Graduate School of Medicine, Akita, Japan; ${ }^{2}$ Division of Public Health, Department of Social Medicine, Nihon University School of Medicine, Tokyo, Japan; ${ }^{3}$ Department of Neuropsychiatry, Kurume University, Fukuoka, Japan; ${ }^{4}$ Department of Somnology, Tokyo Medical University, Tokyo, Japan; ${ }^{5}$ Sleep Disorders Project, Tokyo Metropolitan Institute of Medical Science, Tokyo, Japan; ${ }^{6}$ Division of Bioregulatory Medicine, Department of Katsushika Medical Center The Jikei University, Tokyo, Japan; ${ }^{7}$ Health Promotion and Human Behavior, School of Public Health, Kyoto University Graduate School of Medicine, Kyoto, Japan; ${ }^{8}$ Department of Sleep-Wake Disorders, National Institute of Mental Health, National Center of Neurology and Psychiatry, Tokyo, Japan; 'Department of Psychological Counseling, Faculty of Humanities, Tokyo Kasei University, Tokyo, Japan; ${ }^{10}$ Department of Regional Studies and Humanities, Faculty of Education and Human Studies, Akita University, Akita, Japan; "Department of Environmental Health Science and Public Health, Akita University Graduate School of Medicine, Akita, Japan

Correspondence: Kazuo Mishima Department of Neuropsychiatry, Akita University Graduate School of Medicine, Hondo I-I-I, Akita, 0 I0-8543, Japan

Tel +8I- |8-884-6I 22

Fax +8I- | 8-884-6445

Email mishima@med.akita-u.ac.jp
Purpose: Large-scale natural disasters have an enormous physical and mental impact, immediately after they occur, on people living near the central disaster areas. It is known that, in the early stages, a seismic disaster triggers high rates of symptoms for insomnia, depression, and anxiety. However, little information is available about their medium- to longterm clinical outcomes. In this study, we conducted a repeated cross-sectional nationwide questionnaire survey to clarify changes in the prevalence of insomnia and its background factors after the Great East Japan Earthquake, a huge earthquake with a moment magnitude of 9.0 that occurred on March 11, 2011.

Methods: We conducted a repeated cross-sectional survey in November 2009 (preearthquake, 1224 participants), July 2011 (4 months post-earthquake, 1259 participants), and August 2012 (18 months post-earthquake, 1289 participants) using stratified random sampling from 157 Japanese sites.

Results: Compared to 2009, the prevalence of insomnia statistically increased nationwide immediately post-disaster $(11.7 \%$ vs $21.2 \%$; $p<0.001)$ but significantly decreased in 2012 compared to immediately after the earthquake $(10.6 \%$ vs $21.2 \%$; $p<0.001)$. In 2011 , insomnia was most frequent in the central disaster area. Multivariable logistic regression models demonstrated the association between the following factors and increased risk of insomnia: being a woman (odds ratio [OR] 1.48, 95\% confidence interval [CI]: 1.00-2.19), being employed in 2009 (OR 1.74, 95\% CI: 1.15-2.62), and being of younger age group (20-64 years) in 2011 (OR 1.64, 95\% CI: 1.122.42) and 2012 (OR 2.50 95\% CI: 1.47-4.23). Post-earthquake, the prevalence of insomnia symptoms in men increased, while the gender difference decreased and was no longer statistically significant. Additionally, insomnia was associated with psychological distress (scores $\geq 5$ on the Kessler Psychological Distress Scale) in 2011 and 2012.

Conclusion: This study demonstrated that the prevalence of insomnia was significantly higher after the earthquake. Moreover, individuals with insomnia were more likely to experience psychological distress after the earthquake that continued until 2012.

Keywords: disaster, earthquakes, insomnia, psychological stress

\section{Introduction}

Japan experienced a huge earthquake with a moment magnitude of 9.0 at 14:46 on March 11, 2011. Together with the subsequent tsunami, it resulted in a major catastrophe that caused the death and disappearance of nearly 19,000 residents. The Fukushima Daiichi Nuclear Power Plant was directly hit, which caused a station blackout that, in 
turn, resulted in a Level 7 nuclear power accident. Consequently, anxiety about radiation exposure and power outages persisted even long after the disaster.

One to two months after the seismic disaster, various mental health surveys revealed that approximately $60 \%$ of the local residents experienced some form of insomnia. ${ }^{1-4}$ In normal circumstances, $20-30 \%$ of adults experience insomnia symptoms such as difficulty initiating sleep (DIS), nocturnal awakening, early arousal, or deteriorated sleep quality. ${ }^{5}$ However, during large-scale disasters, the frequency of these symptoms increases sharply two- or three-fold, at least temporarily.

Acute forms of insomnia (short-term insomnia) triggered by seismic disaster-related stress appear to develop into chronic sleep disorders. However, the actual process is unclear. The Diagnostic and Statistical Manual of Mental Disorders, 5th edition, and the International Classification of Sleep Disorders, 3rd edition, define insomnia as the presence of insomnia symptoms that persist for three months or longer, along with various functional disorders such as daytime drowsiness, malaise and depression, decline in psychomotor function, and gastrointestinal symptoms. ${ }^{6,7}$ In normal circumstances, the incidence of insomnia is assumed to be more than $6 \%$ in the general population. ${ }^{5,8-12}$

Chronic sleep disorders reduce the quality of life ${ }^{13}$ and cause personal and socioeconomic losses such as increases in long-term absence from work, reductions in work efficiency, loss of productivity, greater frequency of industrial accidents, and higher medical expenses. ${ }^{1-4,14}$ Insomnia also often coexists with mental illnesses such as mood and anxiety disorders. ${ }^{18-20}$ Further, chronic insomnia is a prodrome of the depression phase ${ }^{21}$ and a risk factor for the onset and recurrence of depression. Thus, the risk of depression among individuals with insomnia is two to three times higher than in those without insomnia. $^{22,23}$

To investigate changes in the prevalence of insomnia and its background factors after the Great East Japan Earthquake, we had conducted a repeated cross-sectional nationwide questionnaire survey in Japan, 4 and 18 months after the earthquake, and compared the results with data from surveys conducted before the earthquake.

\section{Methods}

\section{Sample and Methods}

Participant Selection and Method of Investigation

As part of a research project funded by the Ministry of Health, Labour and Welfare, we first conducted two cross-sectional surveys - one in July 2011 (4 months after the earthquake) and another in September 2012 (18 months after the earthquake)each over a one-month period to examine Japanese residents' sleep status. We used the results of another cross-sectional survey conducted in November 2009, 16 months before the earthquake, as the control data to determine participants' working status, rest, sleep habits, and insomnia symptoms. The three cross-sectional surveys employed the same investigation method.

To ensure representativeness, we used stratified threestage randomization to select 4000 Japanese residents over 20 years of age. We divided the nation's cities, towns, and villages into 12 blocks (Hokkaido, Tohoku, Kanto, Keihin, Koshinetsu, Hokuriku, Tokai, Kinki, Hanshin, Chugoku, Shikoku, and Kyushu) based on prefecture or city, and 36 groups stratified by the size of the city or county in each block (20 largest cities, other cities, and county areas). Additionally, 157 sites were selected using the basic unit wards of the survey area established at the time of the 2005 census and adjusted so that the number of individuals to be sampled per survey area was 25 . Ultimately, we extracted 157 sites. To select households, we used an electronic residential map database (OA-TOWN II, Zenrin).

Among the 157 sites, we randomly selected one target household from every three households. Within each target household, individuals over 20 years old whose birthdates were closest to the survey implementation month were designated as potential participants. After participant identification, the investigators visited 4000 households during the one-month survey period. The number of eligible participants in 2009, 2011, and 2012 was 2206, 2254, and 2238, respectively. We obtained informed consent from 1224 people in 2009 (response rate=55.5\%), 1259 in 2011 (55.9\%), and 1289 in 2012 (57.6\%). After excluding inadequate or incomplete responses, we analyzed the data of 1223, 1254, and 1281 individuals in 2009, 2011, and 2012, respectively. The survey was conducted by investigators trained in interviewing techniques. The Akita University Graduate School of Medicine Ethics Committee approved this study (approval no. 2522). All participants provided informed consent to take part in this study, in accordance with the Declaration of Helsinki.

\section{Classification of Areas by Disaster Impact}

We used existing data to select the following three areas from the prefectures where the participants resided (Figure 1): 


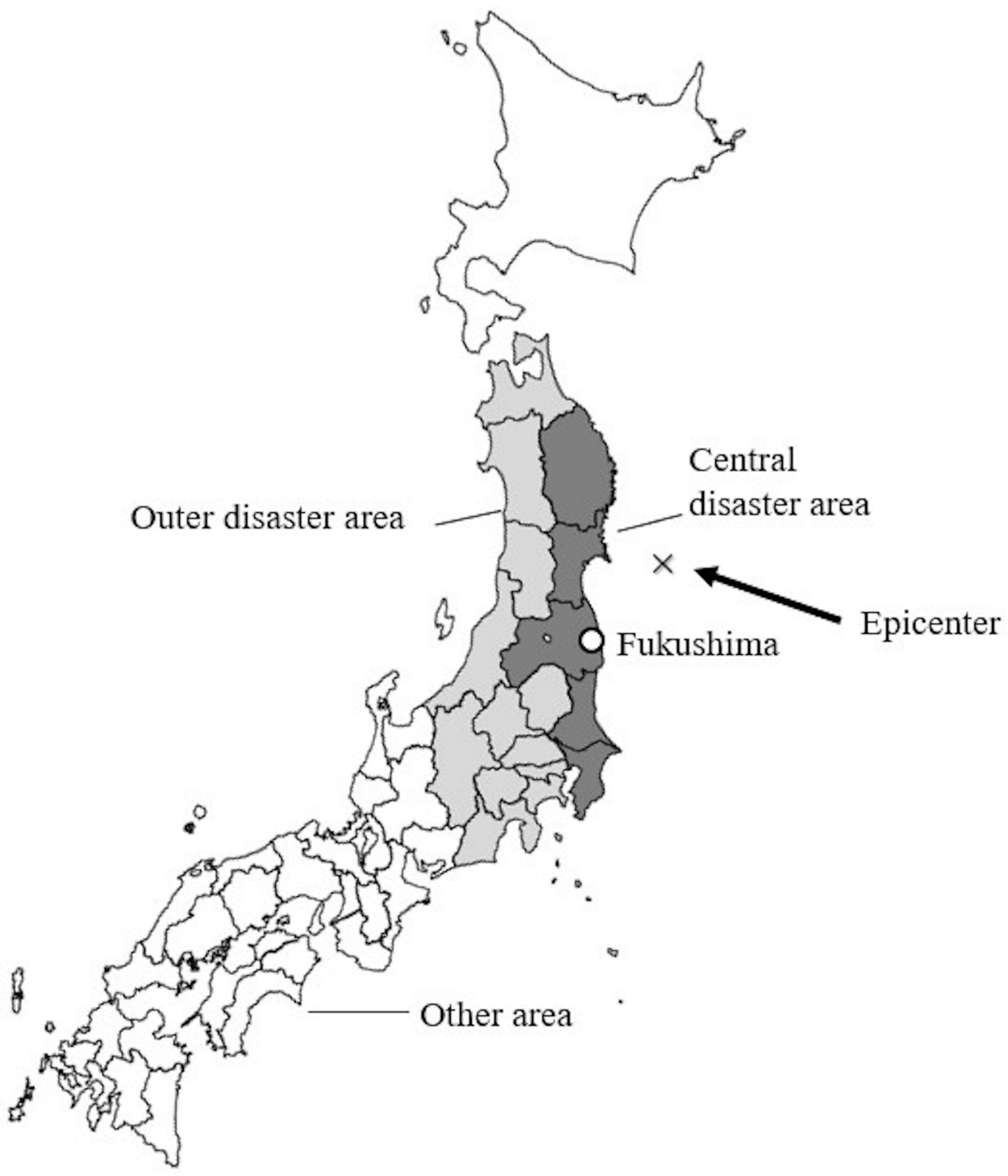

Figure I Map of the central, outer, and other disaster areas.

Notes: Dark gray areas; Five prefectures along the Pacific Coast in Eastern Japan (Iwate, Miyagi, Fukushima, Ibaraki, Chiba: "central disaster area"). These were close to the epicenter, with a maximum seismic impact of more than 6 , and suffered damage because of the inundation of the tsunami. Gray areas; Twelve prefectures that experienced a maximum seismic impact over 6 but were unaffected by the tsunami or experienced a maximum seismic impact of 5-6 (Aomori, Akita, Yamagata, Niigata, Gunma, Tochigi, Saitama, Tokyo, Kanagawa, Yamanashi, Nagano, and Shizuoka: "outer disaster area"). Uncolored area; Areas other than the above that suffered relatively little damage ("other areas").

1. Five prefectures along the Pacific Coast in Eastern Japan (Iwate, Miyagi, Fukushima, Ibaraki, Chiba: "central disaster area"). These were close to the epicenter, with a maximum seismic impact of more than 6, and suffered damage because of the inundation of the tsunami.

2. Twelve prefectures that experienced a maximum seismic impact over 6 but were unaffected by the tsunami or experienced a maximum seismic impact of 5-6 (Aomori, Akita, Yamagata, Niigata, Gunma, Tochigi, Saitama, Tokyo, Kanagawa, Yamanashi, Nagano, and Shizuoka: "outer disaster area").
3. Areas other than the above that suffered relatively little damage ("other areas").

\section{Survey Items \\ Basic Attributes}

For the 3-wave repeated survey, we collected data on the residents' gender, age, and prefecture of residence. Under Japan's current employment system, ages 60-65 correspond with the average mandatory retirement period. Therefore, we established two age groups: (a) the younger age group (aged 20-64) and (b) the older age group (aged 65 and above). 


\section{Evaluation of Insomnia Symptoms}

In the 3-wave repeated survey, we posed the following five questions regarding insomnia symptoms and the presence or absence of related functional disorders, as well as their frequency over the past month:

Q1. Have you had any difficulties falling asleep at night? (difficulty initiating sleep [DIS])

Q2. Have you woken up in the middle of the night and had difficulty getting back to sleep? (difficulty maintaining sleep [DMS])

Q3. Have you woken up early in the morning or at dawn and had difficulty getting back to sleep? (early morning awakening [EMA])

Q4. How do you evaluate your overall sleep quality? (deteriorated sleep quality [DSQ])

Q5. Have you experienced impairments in your life and actions/behaviors during the day because of not getting enough sleep as described above? (eg, fatigue, work performance, concentration, memory, mood, drowsiness, and functional disorders caused by insomnia)

For Q1-3 and Q5, participants had to choose the most applicable response from five options ("Always," "Often," "Sometimes," "Rarely," and "Never"). For Q4, they had to choose from four options ("Very good," "Good," "Bad," and "Very bad").

\section{Definition of Insomnia}

We defined insomnia according to the general criteria in the International Classification of Sleep Disorders: Diagnostic and Coding Manual, 2nd edition., Participants who chose "Sometimes," "Often," or "Always" for Q1-3; "Bad" or "Very bad" for Q4; and "Sometimes," "Often," or "Always" for Q5 were considered to have insomnia.

\section{Evaluation of Post-Earthquake Mental Health}

In the 2011 and 2012 surveys, we used the six-item Kessler Psychological Distress Scale (K6) to evaluate mental health after the earthquake. The K6 was developed to identify depression and anxiety disorders ${ }^{25}$ and has been standardized for use with Japanese samples. ${ }^{26}$ Scores range from 0 to 24 points, and higher scores indicate higher distress severity. A cutoff of 5 was used to identify cases of psychological distress. ${ }^{25,27}$

\section{Statistical Analysis}

The prevalence of insomnia, daytime dysfunction, and any insomnia symptoms between 2009 and 2011 and between
2009 and 2012 was compared with 95\% confidence intervals (CIs) calculated using the Wilson method; $p$-values were estimated using the two-proportions z-test. Similarly, gender, age, and residential area were compared between individuals with and without insomnia in 2009, 2011, and 2012. The chi-square test was used to test the statistical differences between categorical variables, and the $t$-test or Mann-Whitney $U$-test were used for continuous variables. To identify the risk factors for insomnia in 2009, 2011, and 2012, we performed a multivariable logistic regression analysis with simultaneous inclusion of gender, age, education, job groups, and disaster area, and calculated the adjusted odds ratios (ORs) with 95\% CIs.

To analyze post-earthquake mental health status in 2011 and 2012, we first compared the median of continuous K6 scores between individuals with and without insomnia using the Mann-Whitney $U$-test. Then, we explored the relationship between insomnia and the following two K6 categories using the chi-square test: "normal" ( $<5$ points) and "psychological stress-equivalent group" ( $\geq 5$ points).

All analyses were two-tailed and performed using SPSS for Windows version 25.0 (IBM Corp., Armonk, NY, USA). The statistical significance was set at $p<0.05$.

\section{Results}

\section{Participants' Demographic Characteristics}

The gender ratios were $78.5,84.1$, and 80.9 men per 100 women in 2009, 2011, and 2012, respectively, depicting similar ratios across the years. The average age was also similar: 51.0 years (range: 20-98) in 2009, 51.9 years (range: 20-93) in 2011, and 52.8 years (range: 20-93) in 2012; however, the statistical difference was clearly observed between 2009 and $2012(p=0.01)$. For educational attainment, we observed a slightly higher proportion of junior college and university graduates in 2012 compared to 2009. The proportion of participants living in the central disaster area did not significantly vary across the years, with $11.8 \%$ in $2009,12.1 \%$ in 2011 , and $10.6 \%$ in 2012 (Table 1).

\section{Prevalence of Insomnia Before and After the Earthquake}

Table 2 shows the prevalence of insomnia symptoms, daytime dysfunction, and insomnia in 2009, 2011, and 2012. 
Table I Characteristics of Survey Sample Groups

\begin{tabular}{|c|c|c|c|c|c|}
\hline & 2009 & 2011 & 2012 & vs $201 I^{a}$ & vs $2012^{a}$ \\
\hline & $n=1223$ & $n=1254$ & $n=|28|$ & \multicolumn{2}{|c|}{$P^{\mathbf{b}}$} \\
\hline \multicolumn{6}{|l|}{ Gender } \\
\hline Men & $538(44.0)$ & $573(45.7)$ & $573(44.7)$ & 0.39 & $0.7 \mathrm{I}$ \\
\hline Women & $685(56.0)$ & $68 I(54.3)$ & $708(55.3)$ & & \\
\hline \multicolumn{6}{|l|}{ Age } \\
\hline Mean & $51(17.16)$ & $51.9(17.2)$ & $52.8(17.7)$ & 0.20 & 0.01 \\
\hline \multicolumn{6}{|l|}{ Age group } \\
\hline $20-64$ & $909(74.3)$ & $894(71.3)$ & $889(69.4)$ & 0.09 & 0.01 \\
\hline$\geq 65$ & $314(25.7)$ & $360(28.7)$ & $392(30.6)$ & & \\
\hline \multicolumn{6}{|l|}{ Education } \\
\hline Below high school & $158(12.9)$ & $155(12.3)$ & $140(10.9)$ & 0.31 & 0.02 \\
\hline High school & $661(54.0)$ & $648(51.7)$ & $65 I(50.8)$ & & \\
\hline Junior college degree or higher & $404(33.0)$ & $45 \mathrm{I}(36.0)$ & $490(38.3)$ & & \\
\hline \multicolumn{6}{|l|}{ Job group } \\
\hline Agriculture/forestry/fishery & I5 (I.2) & $27(2.1)$ & $12(0.9)$ & 0.23 & 0.32 \\
\hline Commerce/service industry & $125(10.2)$ & $144(\mid 1.5)$ & $15 \mid(11.8)$ & & \\
\hline Office job & $199(16.3)$ & $225(17.9)$ & $221(17.3)$ & & \\
\hline Labor & $287(23.5)$ & $258(20.5)$ & $266(20.8)$ & & \\
\hline Freelance/management & $36(2.9)$ & $27(2.1)$ & $25(2.0)$ & & \\
\hline Housewife & $328(26.8)$ & $336(26.8)$ & 357 (27.9) & & \\
\hline Student & $29(2.4)$ & $25(2.0)$ & $24(1.9)$ & & \\
\hline Other/unemployed & $204(16.7)$ & $212(16.9)$ & $225(17.6)$ & & \\
\hline \multicolumn{6}{|l|}{ Disaster area } \\
\hline Central & $144(\mid \mathrm{I} .8)$ & $152(12.1)$ & $136(10.6)$ & 0.59 & 0.13 \\
\hline Outer & $419(34.3)$ & $45 I(36.0)$ & $488(38.1)$ & & \\
\hline Other & $660(54.0)$ & $65 I(51.9)$ & $657(5 \mid .3)$ & & \\
\hline
\end{tabular}

Notes: ${ }^{a}$ The $p$-values of the chi-square test indicate the comparison of each item between 2009 and 2011 , and between 2009 and $2012 .{ }^{b}$ The reported $p$-values are based on the $\chi^{2}$ test for categorical variables and the independent $t$-test for continuous variables.

In 2009, women had a higher prevalence of insomnia, daytime dysfunction, and insomnia symptoms.

The prevalence of insomnia 4 months after the earthquake (2011) was $21.2 \%$ (95\% CI: 20-23), which was statistically higher than before the disaster $(11.7 \%, 95 \%$ CI: 10.3-13.4). The increased prevalence across all participants, genders, age groups, and areas was found to be decreased in 2012. Regarding gender, in 2011, the prevalence of insomnia was $19.0 \%$ in men and $23.1 \%$ in women. The prevalence of insomnia increased in both genders, but the increase was larger in men (from 8.8\%, 95\% CI: $7.1-11.1$ in 2009 to $19.0 \%, 95 \%$ CI: $16.4-21.8$ in 2011 ) than in women (from $14.1 \%, 95 \%$ CI: $12.0-16.3$ in 2009 to $23.1 \%$, 95\% CI: $20.3-25.7$ in 2011), and the statistically significant difference between men and women that was observed before the earthquake disappeared. Both younger and older age groups suffered from insomnia more in 2011 than in 2009. For the younger age group, the prevalence of insomnia was significantly higher than among those aged 65 or older, both in 2011 (16.9\% vs $22.9 \% ; p=0.02)$ and 2012 (6.9\% vs $12.4 \% ; p<0.01)$.

Across all three areas, the prevalence of insomnia increased compared to that during the pre-disaster period. In particular, the prevalence of insomnia in 2011 was found to be most pronounced in the central disaster area (from 9.7\%, 95\% CI: $6.9-15.3$ in 2009 to $25.7 \%, 95 \%$ CI: $20.3-$ 31.9 in 2011). Furthermore, insomnia was also prevalent in outer disaster areas (from 12.6\%, 95\% CI: 10.2-15.6 in 2009 to $21.7 \%, 95 \%$ CI: $18.6-24.9$ in 2011 ) as well as in other areas (from $11.6 \%, 95 \%$ CI: $9.6-13.7$ in 2009 to $19.8 \%, 95 \%$ CI: 17.3-22.4 in 2011) throughout Japan; however, there was no statistical difference between areas in the same year.

The prevalence of daytime dysfunction of genders across the years was similar to that of insomnia. The prevalence of insomnia symptoms was statistically higher among women in 2009 and 2011. In terms of daytime dysfunction, there was 
Table 2 Prevalence of Insomnia According to Gender, Age, and Disaster Area in 2009-2012

\begin{tabular}{|c|c|c|c|c|c|c|}
\hline \multicolumn{7}{|c|}{ Insomnia } \\
\hline & \multicolumn{2}{|c|}{2009} & \multicolumn{2}{|c|}{2011} & \multicolumn{2}{|c|}{2012} \\
\hline & n (\%) & $95 \% \mathrm{Cl}$ & n (\%) & $95 \% \mathrm{Cl}$ & n (\%) & $95 \% \mathrm{Cl}$ \\
\hline All & I43 (II.7) & $10.3-13.4$ & $266(21.2)^{x}$ & $20-23.1$ & $136(10.6)$ & $9.2-12.0$ \\
\hline \multicolumn{7}{|l|}{ Gender } \\
\hline Men & $47(8.8)$ & 7.I-II.I & $109(19.0)^{x}$ & $|6.4-2| .8$ & $57(9.9)$ & $8.0-12.1$ \\
\hline Women & $96(14.1)^{\mathrm{a}}$ & $12.0-16.3$ & $157(23.1)^{x}$ & $20.3-25.7$ & 79 (11.2) & $9.3-13.2$ \\
\hline \multicolumn{7}{|l|}{ Age group } \\
\hline $20-64$ & $104(11.4)$ & $9.9-16.1$ & $205(22.9)^{\mathrm{bx}}$ & $20.6-25.2$ & $110(12.4)^{\mathrm{b}}$ & $10.7-14.3$ \\
\hline$\geq 65$ & $39(12.4)$ & $9.8-13.3$ & $61(16.9)^{x}$ & 13.9-20.3 & $26(6.6)^{x}$ & $4.7-8.9$ \\
\hline \multicolumn{7}{|l|}{ Education } \\
\hline Less than high school & $24(15.2)$ & II.I-20.5 & $34(21.9)$ & $17.0-27.9$ & $14(10.0)$ & $6.5-15.0$ \\
\hline High school & $70(10.6)$ & $8.8-12.7$ & $129(19.9)^{x}$ & $17.5-22.6$ & $66(10.1)$ & $8.4-12.3$ \\
\hline Junior college or higher & $49(12.1)$ & $9.7-15.1$ & $103(22.8)^{x}$ & $19.8-26.3$ & $56(11.4)$ & $9.3-14.0$ \\
\hline \multicolumn{7}{|l|}{ Job groups } \\
\hline Unemployed & $84(15.0)^{d}$ & $12.7-17.6$ & $123(21.5)^{x}$ & $18.8-24.4$ & $64(10.6)$ & $8.7-12.8$ \\
\hline Employed & $59(8.9)$ & $7.2-10.9$ & $143(21.0)^{x}$ & $18.6-23.7$ & $72(10.7)$ & $8.9-12.8$ \\
\hline \multicolumn{7}{|l|}{ Disaster area } \\
\hline Central & $14(9.7)$ & $6.9-15.3$ & $39(25.7)^{x}$ & $20.3-31.9$ & $19(14.0)$ & $9.7-19.4$ \\
\hline Outer & $53(12.6)$ & $10.2-15.6$ & $98(21.7)^{\times}$ & $18.6-24.9$ & $50(10.2)$ & $8.2-12.7$ \\
\hline Other & $76(11.6)$ & $9.6-13.7$ & $129(19.8)^{x}$ & $17.3-22.4$ & $67(10.2)$ & $8.3-12.2$ \\
\hline \multicolumn{7}{|c|}{ Daytime dysfunction } \\
\hline & \multicolumn{2}{|c|}{2009} & \multicolumn{2}{|c|}{2011} & \multicolumn{2}{|c|}{2012} \\
\hline & n (\%) & $95 \% \mathrm{Cl}$ & n (\%) & $95 \% \mathrm{Cl}$ & n (\%) & $95 \% \mathrm{Cl}$ \\
\hline All & $157(12.8)$ & II.4-I4.6 & $295(23.5)^{x}$ & $21.5-25.5$ & $157(12.3)$ & $10.8-13.8$ \\
\hline \multicolumn{7}{|l|}{ Gender } \\
\hline Men & $52(9.7)$ & $7.9-12.2$ & $118(20.6)^{x}$ & $17.9-23.5$ & $67(11.7)$ & $9.6-14.0$ \\
\hline Women & $105(15.3)^{\mathrm{a}}$ & $13.2-17.7$ & $177(26.0)^{x}$ & $23.2-28.7$ & $90(12.7)$ & $10.7-14.8$ \\
\hline \multicolumn{7}{|l|}{ Age group } \\
\hline 20-64 & $116(12.8)$ & $10.5-16.8$ & $232(26.0)^{b x}$ & $23.5-28.3$ & $130(14.6)^{\mathrm{b}}$ & $12.8-16.6$ \\
\hline$\geq 65$ & $4 I(13.1)$ & $11.1-14.7$ & $63(17.5)$ & $14.4-20.9$ & $27(6.9)^{x}$ & $4.9-9.2$ \\
\hline \multicolumn{7}{|l|}{ Education } \\
\hline Less than high school & $24(15.2)$ & II.I-20.5 & $37(23.9)^{x}$ & $18.7-29.9$ & $14(10.0)$ & $6.5-15.0$ \\
\hline High school & $76(11.5)$ & $9.6-13.7$ & $143(22.1)^{x}$ & $19.5-24.9$ & $78(12.0)$ & $10.0-14.2$ \\
\hline Junior college or higher & $57(14.1)$ & $11.5-17.2$ & $115(25.5)^{x}$ & $22.2-29.0$ & $65(13.3)$ & $10.9-16.0$ \\
\hline \multicolumn{7}{|l|}{ Job groups } \\
\hline Unemployed & $91(16.2)^{d}$ & $13.8-19.0$ & $133(23.2)^{x}$ & $20.4-26.2$ & $70(11.6)$ & $9.6-13.9$ \\
\hline Employed & $66(10.0)$ & $8.2-12.1$ & $162(23.8)^{x}$ & $21.2-26.6$ & $87(12.9)$ & $10.9-15.2$ \\
\hline \multicolumn{7}{|l|}{ Disaster area } \\
\hline Central & $16(11.1)$ & $8.0-16.8$ & $39(25.7)^{x}$ & $20.3-31.9$ & $21(15.4)$ & $10.9-2 \mid .1$ \\
\hline Outer & $59(14.1)$ & $11.5-17.1$ & III $(24.6)^{x}$ & $21.3-27.9$ & $62(12.7)$ & $10.4-15.4$ \\
\hline Other & $82(12.4)$ & $10.5-14.7$ & $145(22.3)^{x}$ & $19.7-25.0$ & $74(11.3)$ & $9.3-13.3$ \\
\hline \multicolumn{7}{|c|}{ Any insomnia symptoms } \\
\hline & \multicolumn{2}{|c|}{2009} & \multicolumn{2}{|c|}{2011} & \multicolumn{2}{|c|}{2012} \\
\hline & n (\%) & $95 \% \mathrm{Cl}$ & n (\%) & $95 \% \mathrm{Cl}$ & n (\%) & $95 \% \mathrm{Cl}$ \\
\hline $\begin{array}{l}\text { All } \\
\text { Gender }\end{array}$ & $537(43.9)$ & $41.6-46.3$ & $635(50.6)^{x}$ & $48.3-52.9$ & $545(42.5)$ & $40.3-44.8$ \\
\hline
\end{tabular}

(Continued) 
Table 2 (Continued).

\begin{tabular}{|c|c|c|c|c|c|c|}
\hline \multicolumn{7}{|c|}{ Any insomnia symptoms } \\
\hline & \multicolumn{2}{|c|}{2009} & \multicolumn{2}{|c|}{2011} & \multicolumn{2}{|c|}{2012} \\
\hline & n (\%) & $95 \% \mathrm{Cl}$ & n (\%) & $95 \% \mathrm{Cl}$ & n (\%) & $95 \% \mathrm{Cl}$ \\
\hline Men & $209(38.8)$ & $35.6-42.5$ & $267(46.6)^{x}$ & $43.1-50$ & $229(40.0)$ & $36.7-43.3$ \\
\hline Women & $328(47.9)^{\mathrm{a}}$ & $44.8-51.0$ & $368(54.0)^{\mathrm{a}}$ & $50.9-57.1$ & $316(44.6)$ & $41.6-47.7$ \\
\hline \multicolumn{7}{|l|}{ Age group } \\
\hline $20-64$ & $387(42.6)$ & $39.9-45.3$ & $447(50.0)^{x}$ & $47.3-52.8$ & $350(39.4)^{b}$ & $36.6-42.0$ \\
\hline$\geq 65$ & $150(47.8)$ & $43.3-52.6$ & $188(52.2)$ & $47.6-56.2$ & $195(49.7)$ & $45.4-53.6$ \\
\hline \multicolumn{7}{|l|}{ Education } \\
\hline Less than high school & $87(55.1)^{c}$ & $48.5-61.4$ & $79(51.0)$ & $44.4-57.5$ & $61(43.6)$ & $36.9-50.5$ \\
\hline High school & $294(44.5)$ & $41.3-47.7$ & $335(51.7)^{x}$ & $48.5-54.9$ & $278(42.7)$ & $39.6-45.9$ \\
\hline Junior college or higher & $156(38.6)$ & $34.6-42.3$ & $221(49.0)^{x}$ & $45.2-52.9$ & $206(42.0)$ & $38.4-45.7$ \\
\hline Job groups & & & & & & \\
\hline Unemployed & $282(50.3)^{d}$ & $46.8-53.7$ & $313(54.6)^{d}$ & $51.2-58.0$ & $294(48.5)^{d}$ & $45.2-51.9$ \\
\hline Employed & $255(38.5)$ & $35.5-41.7$ & $322(47.3)^{x}$ & $44.2-50.4$ & $25 \mathrm{I}(37.2)$ & $34.2-40.3$ \\
\hline \multicolumn{7}{|l|}{ Disaster area } \\
\hline Central & $54(37.5)$ & $31.6-44.7$ & $73(48.0)$ & $41.5-54.7$ & $65(47.8)$ & $40.8-54.8$ \\
\hline Outer & $205(48.9)$ & $44.9-52.9$ & $230(51.0)$ & $45.5-53.2$ & $198(40.6)$ & $37-44.3$ \\
\hline Other & $278(42.1)$ & $39-45.3$ & $332(51.0)^{x}$ & $45.7-52.1$ & $282(42.9)$ & $39.8-46.1$ \\
\hline
\end{tabular}

Notes: ${ }^{x} p<0.05$ vs $2009,{ }^{a} p<0.05$ vs men, ${ }^{b} p<0.05$ vs $\geq 65$ years, ${ }^{c} p<0.05$ vs other education, ${ }^{d} p<0.05$ vs employed.

Abbreviation: $\mathrm{Cl}$, confidence interval.

no significant difference among the age groups before the earthquake; however, there was a notable increase in this among the younger age group immediately after and 18 months after the earthquake, which was statistically significantly higher than that observed in the older age group. On the other hand, there was no statistically significant difference in any insomnia symptoms among the age groups in 2009 and 2011. In terms of employment status, the prevalence of insomnia and daytime dysfunction was significantly higher in the unemployed than in the employed before the earthquake; however, immediately after the earthquake, this prevalence among the employed increased significantly and no difference was observed. The prevalence of any insomnia symptoms was consistently higher in the unemployed than in the employed both before and after the earthquake.

The prevalence of each insomnia symptom also increased immediately after the earthquake compared to before the earthquake. The overall prevalence of difficulty initiating sleep was significantly higher before and after the earthquake compared to other insomnia symptoms (Supporting Table S1).

\section{Risk of Insomnia: Logistic Regression Analyses}

Table 3 summarizes the insomnia risk calculated using logistic regression analyses. The following factors were associated with increased insomnia risk: being a woman (OR: 1.48, 95\% CI: 1.00-2.19) and being employed in 2009 (OR: 1.74, 95\% CI: 1.15-2.62). After the earthquake, gender differences in the prevalence of insomnia symptoms narrowed and the OR of insomnia among women (vs men) decreased from 1.48 times before the earthquake to 1.24 times after the earthquake, making the difference statistically non-significant.

Furthermore, in terms of age group, no significant differences were observed between the younger and older age groups before the earthquake. However, the younger age group was associated with the risk of insomnia 4 and 18 months after the earthquake (OR: $1.26,95 \%$ CI: $0.78-$ 2.06 in 2009, OR: $1.64,95 \%$ CI: $1.12-2.42$ in 2011, OR: $2.5095 \%$ CI: $1.47-4.23$ in 2012; for the p-values and raw ORs, see Supporting Table S2).

\section{Mental Health Status After the Earthquake}

Table 4 presents the participants' post-earthquake mental health status. The K6 scores of participants with insomnia, both 4 and 18 months after the earthquake, were significantly higher than those of participants without insomnia. Compared to participants without insomnia, a significantly higher proportion of those with insomnia (men and 


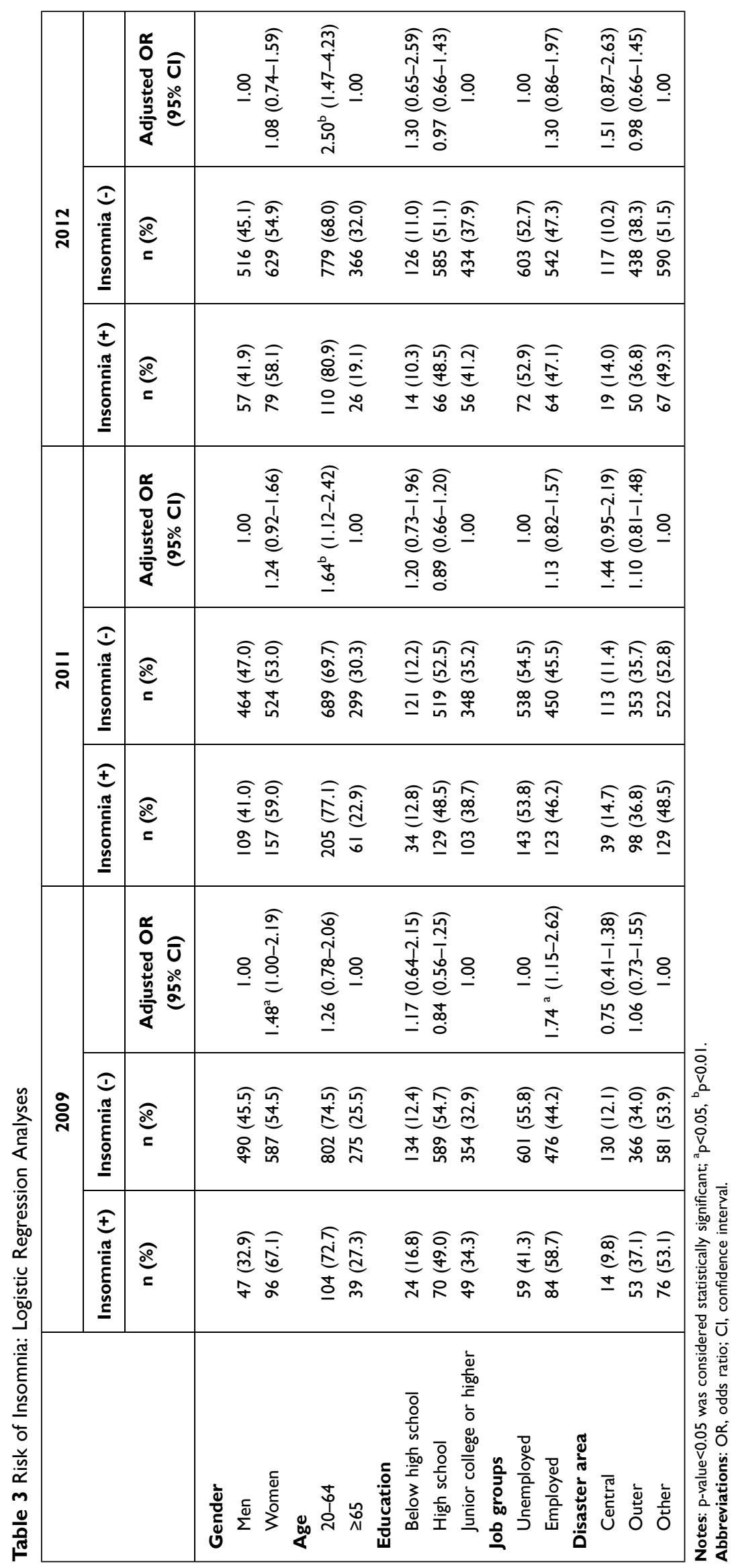


Table 4 Post-Earthquake Mental Health Status (K6)

\begin{tabular}{|c|c|c|c|c|c|c|c|c|}
\hline & & \multicolumn{7}{|c|}{2011} \\
\hline & \multirow[b]{2}{*}{$\begin{array}{l}\text { K6 } \\
\text { score }^{b}\end{array}$} & \multicolumn{2}{|l|}{ All } & \multicolumn{2}{|c|}{ Non-Insomnia } & \multicolumn{3}{|c|}{ Insomnia } \\
\hline & & n or median & $\begin{array}{l}\% \text { or } \\
\text { IQR }\end{array}$ & n or median & $\%$ or IQR & n or median & $\%$ or IQR & $p$ \\
\hline \multirow[t]{3}{*}{ All } & & 0 & $0-2$ & 0 & $0-1$ & 3 & $0-6$ & $<0.01$ \\
\hline & $<5$ & 1081 & $86.2 \%$ & 908 & $91.9 \%$ & 173 & $65.0 \%$ & $<0.01$ \\
\hline & $\geq 5$ & 173 & $13.8 \%$ & 80 & $8.1 \%$ & 93 & $35.0 \%$ & \\
\hline \multirow[t]{2}{*}{ Men } & $<5$ & 501 & $87.4 \%$ & 430 & $92.7 \%$ & 71 & $65.1 \%$ & $<0.01$ \\
\hline & $\geq 5$ & 72 & $12.6 \%$ & 34 & $7.3 \%$ & 38 & $34.9 \%$ & \\
\hline \multirow[t]{2}{*}{ Women } & $<5$ & 580 & $85.2 \%$ & 478 & $91.2 \%$ & 102 & $65.0 \%$ & $<0.01$ \\
\hline & $\geq 5$ & 101 & $14.8 \%$ & 46 & $8.8 \%$ & 55 & $35.0 \%$ & \\
\hline & & \multicolumn{7}{|c|}{2012} \\
\hline & & \multicolumn{2}{|l|}{ All } & \multicolumn{2}{|c|}{ Non-Insomnia } & \multicolumn{3}{|c|}{ Insomnia } \\
\hline & $\begin{array}{l}\text { K6 } \\
\text { score }^{b}\end{array}$ & n or median & $\begin{array}{l}\% \text { or } \\
\text { IQR }\end{array}$ & $\mathrm{n}$ or median & $\%$ or IQR & n or median & $\%$ or IQR & $p$ \\
\hline \multirow[t]{3}{*}{ All } & & 1.52 & $0-2$ & 0 & $0-1$ & 3 & $\mathrm{I}-8$ & $<0.01$ \\
\hline & $<5$ & $|13|$ & $88.3 \%$ & 1053 & $92.0 \%$ & 78 & $57.4 \%$ & $<0.01$ \\
\hline & $\geq 5$ & 150 & $11.7 \%$ & 92 & $8.0 \%$ & 58 & $42.6 \%$ & \\
\hline \multirow[t]{2}{*}{ Men } & $<5$ & 505 & $88.1 \%$ & 470 & $91.1 \%$ & 35 & $61.4 \%$ & $<0.01$ \\
\hline & $\geq 5$ & 68 & $11.9 \%$ & 46 & $8.9 \%$ & 22 & $38.6 \%$ & \\
\hline \multirow[t]{2}{*}{ Women } & $<5$ & 626 & $88.4 \%$ & 583 & $92.7 \%$ & 43 & $54.4 \%$ & $<0.01$ \\
\hline & $\geq 5$ & 82 & $11.6 \%$ & 46 & $7.3 \%$ & 36 & $45.6 \%$ & \\
\hline
\end{tabular}

Notes: ${ }^{a}$ The reported $\mathrm{p}$-values are based on the $\chi^{2}$ test for categorical variables and the Mann-Whitney $U$-test for continuous variables, comparing insomnia and noninsomnia groups. ${ }^{\text {b}}$ The scores range from 0 to 24 points; higher scores indicate higher distress severity. A cutoff of 5 was used to identify cases of psychological distress. Abbreviation: IQR, interquartile range.

women) experienced psychological distress (K6 score $\geq 5$; $35.0 \%$ vs $8.1 \%$ ) 4 months after the earthquake. There was no significant difference in the prevalence of psychological distress across genders regardless of the prevalence of insomnia. The proportion of participants with insomnia and psychological distress was higher 18 months after the earthquake than what was observed at 4 months.

\section{Discussion}

The Great East Japan Earthquake was the largest megaearthquake recorded in and around Japan. According to the United States Geological Survey, it was the world's fourth largest earthquake since 1900. The subsequent tsunami reached a height of 40.5 meters, the highest-ever in recorded Japanese history. The death toll reached 15,899, 2529 people went missing, and 6157 were injured. Approximately 1 million homes and buildings were damaged and over 300,000 residents became evacuees. Moreover, long after the earthquake, the Fukushima nuclear accident caused significant psychological distress among affected residents, especially mothers of infants and people working at the nuclear power plant. Reportedly, changes in physical health, including sleep and eating disorders, were also observed. ${ }^{28}$

The results of this 3 -wave repeated survey reveal that compared to the scenario before the earthquake (November 2009; 11.7\%), the prevalence of insomnia sharply increased 4 months after the disaster (July 2011; $21.2 \%$ ). Further, the prevalence of insomnia in 2011 was most notable in the central disaster area at $25.7 \%$ (November 2009; 9.7\%), reaching 2.7-fold higher than before the disaster. Not as much as the central area, the rate of increase was also high in the outer $(21.7 \%)$ and other disaster areas (19.8\%), reaching 1.7-fold. Thus, the Great East Japan Earthquake not only triggered insomnia at extremely high rates in the central disaster area, which suffered substantial destruction but also in areas that suffered little direct damage. The marked increase in the prevalence of insomnia throughout Japan appears to have been caused by various factors, such as the sheer scale of 
the earthquake, widespread damage, and prolongation of secondary damage. Sugiura et al also stated that the rate of insomnia increased immediately after the Great East Japan Earthquake, even in areas far from the epicenter, and concluded that the unsettling images shown on television and other media might have contributed to the incidence of insomnia. $^{28}$

Studies of affected people of large-scale natural disasters have confirmed that sleep disorders are a common occurrence. Immediately after the earthquakes that occurred in Loma Prieta, California in $1989 ;{ }^{29}$ HanshinAwaji, Japan, in $1995 ;^{3}$ Taiwan in $1999 ;^{4}$ Athens, Greece, in $1999 ;^{1}$ Sumatra, Indonesia, in $2004 ;^{2}$ and Kefalonia Island, Greece, in $2014,{ }^{30}$ approximately $60 \%$ of the disaster affected people experienced insomnia symptoms and nightmares (after three to eight weeks). As our 2011 survey was conducted 4 months after the earthquake, the prevalence of insomnia symptoms was lower than that in the aforementioned studies. Nevertheless, the prevalence of DIS, which was the most common symptom, exceeded $40 \%$.

Several epidemiological studies have reported that the prevalence of insomnia symptoms is high among women. ${ }^{5,22,31-35}$ A similar pattern was observed in this study. However, after the earthquake, gender differences in the prevalence of insomnia symptoms narrowed, and the OR of insomnia among women (vs men) decreased after the earthquake, making the difference statistically nonsignificant.

In terms of age group, no significant differences were observed between the younger age group and the older age group before the earthquake. However, 4 months after the earthquake, insomnia risk among the younger age group increased sharply compared to the older age group. Moreover, 18 months later, insomnia risk among the younger age group further increased. This indicates that vulnerability to insomnia after exposure to psychological, social, and economic stress due to the Great East Japan Earthquake was higher among the younger age group. Van Griensven et al reported that symptoms of PTSD, anxiety, and depression were significantly higher in the younger age group among the Sumatra earthquake evacuees. ${ }^{2}$ In addition, Kato et al reported that depressive symptoms were frequently observed in the younger age group immediately after the Hanshin-Awaji earthquake in Japan. ${ }^{3}$ Although the reason for this high prevalence of postdisaster insomnia among the younger age group is not clear, we speculate that the psychological distress of rebuilding their lives and their families, besides finding new employment, may have been greater for the younger age group than for the older age group, who are retired and financially stable with pensions. As for the effect of employment status on insomnia, we speculate that this effect was reflected in the skewed age distribution, as the unemployed included more persons from the older age group and the employed included more from the younger age group.

However, a literature review of resilience in the elderly has shown that elderly people are not necessarily vulnerable to stress but rather are capable of high resilience. ${ }^{37}$ In a recent study in Italy that examined the relationship between stressful events related to the lockdown caused by the COVID-19 pandemic and mental health, the resilience of older adults was also found to be less affected by stressful events, which may be one of the reasons for the favorable mental health outcomes seen in older adults. ${ }^{36}$ These findings may partly explain the reasons for the favorable sleep and mental health outcomes observed in the elderly after the Great East Japan Earthquake in the present study.

In the context of post-disaster mental health, a higher proportion of those with insomnia immediately after the earthquake achieved scores that indicated psychological distress ( $\geq 5$ points on the K6), strongly suggesting the deterioration of mental health problems. The prevalence of insomnia in 2012 dropped below that in 2011 and was almost the same as in 2009. In contrast, the ratio of high K6 scores worsened within the insomnia group. The prevalence rate of insomnia seems to have risen in 2011 owing to temporary stress reactions associated with the earthquake. Nonetheless, one year later, many participants with acute insomnia symptoms had recovered. However, one year after the disaster, participants with residual insomnia included many who experienced mental health problems. Oyama et al reported that being young $(<49$ years), loss of contact with people in the community, and lack of employment were associated with higher prevalence of psychological distress in a survey conducted three years after the 2004 Niigata-Chuetsu earthquake. ${ }^{38}$ The survey reported that the prevalence of pregnant women with psychological distress did not decrease three years after the Great East Japan Earthquake, a point that should be noted. ${ }^{39}$ Suzuki et al reported that the risk of depressive tendencies was higher in men who were not working and aged $<60$ years, compared with those who were working. ${ }^{40}$ Considering that insomnia symptoms appear before 
anxiety and mood disorders and that chronic insomnia increases the occurrence and risk of recurrence of such disorders, ${ }^{21,23}$ the outcomes for individuals with insomnia long after the earthquake must be carefully reassessed, with special attention paid to this population.

Caution must be exercised when interpreting our results. Since this was not a longitudinal study and was a three-wave repeated survey, it targeted different participants. Therefore, we could not compare the results directly and need to carefully examine whether the yearly increase/decrease trends are truly causal. Moreover, we could not obtain K6 data for the 2009 survey; this prevented a direct comparison of mental health before and after the disaster. Additionally, the earthquake cannot be considered the only contributing factor because, in most cases, the causes of insomnia are multi-layered. Needless to say, those with insomnia after an earthquake include those whose relationship to the disaster is unclear. Furthermore, there is a possibility that some of the people living in the central disaster area were not able to participate in this survey because of serious mental or physical damage. Finally, since we were unable to obtain data on the respondents' history of hospital treatment, medication, and mental illness; employment status such as shift work; economic status; loss of family and acquaintances because of the earthquake; and the presence or absence of building damage; and whether they had lost their job, we could not conduct further analysis of insomnia based on cause, or confirm how these factors impacted insomnia symptoms. Therefore, future research should utilize a survey using structured interviews with detailed questions about the participants' condition as well as evaluation tests such as polysomnography, the State-Trait Anxiety Inventory, Quick Inventory of Depressive Symptomatology, and Patient Health Questionnaire-9 to understand anxiety and depression, objectively assess sleep status, and obtain detailed information about the subjects. We would like to perform a 4th wave of research using the same methods to observe the effects 10 years after the Great East Japan Earthquake as well as the current COVID-19, in order to understand the resilience of affected people. Future studies need to demonstrate sufficient ethical considerations to avoid any additional psychological burden on the research participants who may have suffered psychological distress.

\section{Conclusions}

The 3-wave repeated survey with cross-sectional design was conducted in 2009, 2011, and 2012 to investigate the associations between the Great East Japan Earthquake and sleep status and mental health. In the wake of the earthquake, the prevalence of insomnia increased throughout Japan and the increase was especially pronounced in the central disaster area. Additionally, the prevalence of insomnia also increased after the disaster in both men and women, but the prevalence of insomnia increased more markedly in men. Furthermore, by age, the prevalence of insomnia increased significantly in the younger age groups 4 months after the earthquake and 18 months after the earthquake. Moreover, those with insomnia included a high proportion of individuals with psychological distress, with no recovery trend observed 18 months after the earthquake. We believe that it is necessary to introduce therapeutic interventions, including psychological and physical interventions, as early as possible in order to prevent the prolongation of post-disaster insomnia and the resulting daytime dysfunction. Early detection is imperative for accurate diagnoses and appropriate treatment. Further, survivors require long-term monitoring.

\section{Abbreviations}

CI, confidence interval; DIS, difficulty initiating sleep; DMS, difficulty maintaining sleep; DSQ, deteriorated sleep quality; EMA, early morning awakening; K6, Kessler Psychological Distress Scale; OR, odds ratio.

\section{Data Sharing Statement}

The datasets used and/or analyzed during the current study are available from the corresponding author on reasonable request.

\section{Ethics Approval and Consent to Participate}

The Akita University Graduate School of Medicine Ethics Committee approved this study (approval no. 2522).

\section{Acknowledgments}

We thank Dr Sawako Minamizono for her advice and assistance with the statistical analysis. $\mathrm{Dr}$ Norio Watanabe is now affiliated with the Department of Psychiatry, Soseikai General Hospital, Kyoto, Japan.

\section{Author Contributions}

All authors made a significant contribution to the work reported, whether that is in the conception, study design, execution, acquisition of data, analysis and interpretation, or in all these areas; took part in drafting, revising or 
critically reviewing the article; gave final approval of the version to be published; have agreed on the journal to which the article has been submitted; and agree to be accountable for all aspects of the work.

\section{Funding}

This study was supported by research grants from the Japanese Ministry of Health, Labour, and Welfare (ID: 22172001).

\section{Disclosure}

Dr Makoto Honda reports personal fees from Takeda Pharmaceutical Co Ltd, Ono Pharmaceutical Co Ltd, and Alfresa Corporation, outside the submitted work. The authors report no other conflicts of interest in this work.

\section{References}

1. Varela E, Koustouki V, Davos CH, Eleni K. Psychological consequences among adults following the 1999 earthquake in Athens, Greece. Disasters. 2008;32:280-291. doi:10.1111/j.14677717.2008.01039.x

2. van Griensven F, Chakkraband ML, Thienkrua W, et al. Mental health problems among adults in tsunami-affected areas in southern Thailand. JAMA. 2006;296:537-548. doi:10.1001/jama.296.5.537

3. Kato H, Asukai N, Miyake Y, Minakawa K, Nishiyama A. Posttraumatic symptoms among younger and elderly evacuees in the early stages following the 1995 Hanshin-Awaji earthquake in Japan. Acta Psychiatr Scand. 1996;93:477-481. doi:10.1111/j.16000447.1996.tb10680.x

4. Chen CC, Yeh TL, Yang YK, et al. Psychiatric morbidity and post-traumatic symptoms among survivors in the early stage following the 1999 earthquake in Taiwan. Psychiatry Res. 2001;105:13-22. doi:10.1016/s0165-1781(01)00334-1

5. Ohayon MM. Epidemiology of insomnia: what we know and what we still need to learn. Sleep Med Rev. 2002;6:97-111. doi:10.1053/ smrv.2002.0186

6. American Psychiatric Association. Diagnostic and Statistical Manual of Mental Disorders. 5th ed. Washington, DC: American Psychiatric Association; 2013.

7. American Academy of Sleep Medicine. International Classification of Sleep Disorders. 3rd ed. Darlen: American Academy of Sleep Medicine; 2014.

8. Morin CM, LeBlanc M, Daley M, Gregoire JP, Merette C. Epidemiology of insomnia: prevalence, self-help treatments, consultations, and determinants of help-seeking behaviors. Sleep Med. 2006;7:123-130. doi:10.1016/j.sleep.2005.08.008

9. Ford DE, Kamerow DB. Epidemiologic study of sleep disturbances and psychiatric disorders. An opportunity for prevention? JAMA. 1989;262:1479-1484. doi:10.1001/jama.262.11.1479

10. Mellinger GD, Balter MB, Uhlenhuth EH. Insomnia and its treatment. Prevalence and correlates. Arch Gen Psychiatry. 1985;42:225-232. doi:10.1001/archpsyc.1985.01790260019002

11. Buysse DJ, Angst J, Gamma A, Ajdacic V, Eich D, Rossler W. Prevalence, course, and comorbidity of insomnia and depression in young adults. Sleep. 2008;31:473-480. doi:10.1093/sleep/31.4.473

12. Kim K, Uchiyama M, Okawa M, Liu X, Ogihara R. An epidemiological study of insomnia among the Japanese general population. Sleep. 2000;23:41-47. doi:10.1093/sleep/23.1.1a
13. Zammit GK, Weiner J, Damato N, Sillup GP, McMillan CA. Quality of life in people with insomnia. Sleep. 1999;22 Suppl 2:S379-385.

14. Balbo M, Leproult R, Van Cauter E. Impact of sleep and its disturbances on hypothalamo-pituitary-adrenal axis activity. Int J Endocrinol. 2010;2010:1-16. doi:10.1155/2010/759234

15. Sivertsen B, Overland S, Neckelmann D, et al. The long-term effect of insomnia on work disability: the HUNT-2 historical cohort study. Am J Epidemiol. 2006;163:1018-1024. doi:10.1093/aje/kwj145

16. Ozminkowski RJ, Wang S, Walsh JK. The direct and indirect costs of untreated insomnia in adults in the United States. Sleep. 2007;30:263-273. doi:10.1093/sleep/30.3.263

17. Simon GE, VonKorff M. Prevalence, burden, and treatment of insomnia in primary care. Am $J$ Psychiatry. 1997;154:1417-1423. doi:10.1176/ajp.154.10.1417

18. Taylor DJ, Lichstein KL, Durrence HH, Reidel BW, Bush AJ. Epidemiology of insomnia, depression, and anxiety. Sleep. 2005;28:1457-1464. doi:10.1093/sleep/28.11.1457

19. Tsuno N, Besset A, Ritchie K. Sleep and depression. J Clin Psychiatry. 2005;66:1254-1269. doi:10.4088/jcp.v66n1008

20. Johnson EO, Roth T, Breslau N. The association of insomnia with anxiety disorders and depression: exploration of the direction of risk. J Psychiatr Res. 2006;40:700-708. doi:10.1016/j.jpsy chires.2006.07.008

21. Perlis ML, Giles DE, Buysse DJ, Tu X, Kupfer DJ. Self-reported sleep disturbance as a prodromal symptom in recurrent depression. $J$ Affect Disord. 1997;42:209-212. doi:10.1016/s0165-0327(96) 01411-5

22. Morphy H, Dunn KM, Lewis M, Boardman HF, Croft PR. Epidemiology of insomnia: a longitudinal study in a UK population. Sleep. 2007;30:274-280.

23. Baglioni C, Battagliese G, Feige B, et al. Insomnia as a predictor of depression: a meta-analytic evaluation of longitudinal epidemiological studies. J Affect Disord. 2011;135:10-19. doi:10.1016/j. jad.2011.01.011

24. American Academy of Sleep Medicine. International Classification of Sleep Disorders, Diagnostic and Coding Manual. 2nd ed. Darlen IL: American Academy of Sleep Medicine; 2005.

25. Kessler RC, Andrews G, Colpe LJ, et al. Short screening scales to monitor population prevalences and trends in non-specific psychological distress. Psychol Med. 2002;32:959-976. doi:10.1017/ s0033291702006074

26. Furukawa TA, Kawakami N, Saitoh M, et al. The performance of the Japanese version of the K6 and K10 in the World Mental Health Survey Japan. Int J Methods Psychiatr Res. 2008;17:152-158. doi: $10.1002 / \mathrm{mpr} .257$

27. Sakurai K, Nishi A, Kondo K, Yanagida K, Kawakami N. Screening performance of K6/ K10 and other screeninginstruments for mood and anxiety disorders in Japan. Psychiatry Clin Neurosci. 2011;65 (5):434-441.doi:10.1111/j.1440-1819.2011.02236.x

28. Sugiura H, Akahane M, Ohkusa Y, et al. Prevalence of insomnia among residents of Tokyo and Osaka after the great East Japan earthquake: a prospective study. Interact J Med Res. 2013;2:e2. doi:10.2196/ijmr.2485

29. Wood JM, Bootzin RR, Rosenhan D, Nolen-Hoeksema S, Jourden F. Effects of the 1989 San Francisco earthquake on frequency and content of nightmares. J Abnorm Psychol. 1992;101:219-224. doi:10.1037//0021-843x.101.2.219

30. Lazaratou H, Paparrigopoulos T, Anomitri C, Alexandropoulou N, Galanos G, Papageorgiou C. Sleep problems six-months after continuous earthquake activity in a Greek island. Psychiatriki. 2018;29:25-33. doi:10.22365/jpsych.2018.291.25

31. Chevalier H, Los F, Boichut D, et al. Evaluation of severe insomnia in the general population: results of a European multinational survey. J Psychopharmacol. 1999;13:S21-24. doi:10.1177/026988 $119901304 \mathrm{~s} 04$ 
32. Olson LG. A community survey of insomnia in Newcastle. Aust $N \quad Z \quad J$ Public Health. 1996;20:655-657. doi:10.1111/j.1467842x.1996.tb01083.x

33. Dodge R, Cline MG, Quan SF. The natural history of insomnia and its relationship to respiratory symptoms. Arch Intern Med. 1995;155:1797-1800. doi:10.1001/archinte.1995.00430160145014

34. Krystal AD. Insomnia in women. Clin Cornerstone. 2003;5:41-50. doi:10.1016/s1098-3597(03)90034-2

35. Hajak G. Epidemiology of severe insomnia and its consequences in Germany. Eur Arch Psychiatry Clin Neurosci. 2001;251:49-56. doi:10.1007/s004060170052

36. Rossi R, Jannini TB, Socci V, Pacitti F, Lorenzo GD. Stressful life events and resilience during the COVID-19 lockdown measures in Italy: association with mental health outcomes and age. Front Psychiatry. 2021;12:635832. doi:10.3389/fpsyt.2021.635832
37. MacLeod S, Musich S, Hawkins K, Alsgaard K, Wicker ER. The impact of resilience among older adults. Geriatr Nurs. 2016;37:266-272. doi:10.1016/j.gerinurse.2016.02.014

38. Oyama M, Nakamura K, Suda Y, Someya T. Social network disruption as a major factor associated with psychological distress 3 years after the 2004 Niigata-Chuetsu earthquake in Japan. Environ Health Prev Med. 2012;17:118-123. doi:10.1007/s12199-011-0225-y

39. Tanoue K, Watanabe Z, Nishigori H, et al. The prevalence of psychological distress during pregnancy in Miyagi Prefecture for 3 years after the Great East Japan Earthquake. Environ Health Prev Med. 2021;26:27. doi:10.1186/s12199-021-00944-2

40. Suzuki H, Kadota A, Okuda N, et al. Socioeconomic and lifestyle factors associated with depressive tendencies in general Japanese men and women: NIPPON DATA2010. Environ Health Prev Med. 2019;24:37. doi:10.1186/s12199-019-0788-6

\section{Publish your work in this journal}

Nature and Science of Sleep is an international, peer-reviewed, open access journal covering all aspects of sleep science and sleep medicine, including the neurophysiology and functions of sleep, the genetics of sleep, sleep and society, biological rhythms, dreaming, sleep disorders and therapy, and strategies to optimize healthy sleep.
The manuscript management system is completely online and includes a very quick and fair peer-review system, which is all easy to use. Visit http://www.dovepress.com/testimonials.php to read real quotes from published authors. 